\title{
PROPOSTAS INTERACIONISTAS EM PEDAGOGIA DO ESPORTE: APROXIMAÇÕES E CARACTERÍSTICAS
}

Leopoldo Kastsuki Hirama - Universidade Estadual de Campinas - UNICAMP, Campinas, São Paulo - Brasil

Cássia dos Santos Joaquim - Universidade Estadual de Campinas - UNICAMP, Campinas, São Paulo - Brasil

Roberto Rocha Costa - Universidade Estadual de Campinas - UNICAMP, Campinas, São Paulo-Brasil

Paulo César Montagner - Universidade Estadual de Campinas - UNICAMP, Campinas, São Paulo-Brasil

\section{RESUMO}

Propostas interacionistas vêm sendo formuladas e refletidas desde o final do século passado com o objetivo de oferecer alternativa de ensino do esporte de forma a superar propostas tradicionais que podem desenvolver em sua prática algumas características bastante discutidas e consideradas inadequadas, como a exclusão, a especialização precoce, a mecanização de técnicas em detrimento da compreensão da modalidade, entre outros. Considera-se dentro da denominação interacionista diversas propostas elaboradas por diferentes autores da pedagogia do esporte. Apesar desta diversidade, várias aproximações são encontradas ao se investigar as proposições, indicando mais semelhanças do que distanciamentos. Desta forma, este estudo tem por objetivo, através da revisão bibliográfica das propostas de alguns autores das pedagogias interacionistas, levantar e discutir as aproximações encontradas nas diferentes publicações. Espera-se que o artigo possa contribuir para o melhor entendimento de tais propostas por parte dos profissionais que lidam com o ensino do esporte, facilitando a compreensão de suas características semelhantes e exemplificando as possibilidades de intervenção.

Palavras-Chave: Metodologia; Pedagogia do esporte; Interacionismo.

\section{INTERACTIONIST PROPOSALS IN SPORT PEDAGOGY: APPROACHES AND FEATURES}

\begin{abstract}
Interactionist proposals are being formulated and reflected from the end of the last century with the goal of providing alternative to teaching the sport in order to overcome traditional proposals that may develop in your practice some fairly discussed features and considered inadequate, as exclusion, early specialization, mechanization of techniques at the expense of understanding the embodiment, among others. Within the interactionist denomination is considered various proposals made by different authors of sport pedagogy. Despite this diversity, several approximations are found when investigate the propositions, indicating more similarities than distancing. Thus, this study aims, through literature review of proposals by some authors of interactionist pedagogies, raise and discuss the similarities found in different publications. It is hoped that the article will contribute to a better
\end{abstract}


understanding of such proposals by the professionals who deal with the teaching of sports, facilitating the understanding of their similar characteristics and exemplifying the possibilities of intervention.

Key-Words: Methodology; Sport pedagogy; Interactionism.

\section{PROPUESTAS INTERACCIONISTAS EN PEDAGOGÍA DEPORTIVA: ENFOQUES Y CARACTERÍSTICAS}

\section{RESUMEN}

Propuestas interaccionistas se están formulando y reflejados desde el final del siglo pasado con el objetivo de proporcionar alternativas enseñanza de este deporte con el fin de superar las propuestas tradicionales que se pueden desarrollar en su práctica algunas características bastante discutidas y consideradas inadecuadas, como la exclusión, la especialización temprana, la mecanización de las técnicas a expensas de la comprensión de la forma de realización, entre otros. Dentro de la denominación interaccionista se considera varias propuestas realizadas por diferentes autores de la pedagogía deportiva. A pesar de esta diversidad, varias aproximaciones se encuentran para investigar las proposiciones, indicando más similitudes que distanciarse. Por lo tanto, este estudio tiene como objetivo, a través de revisión de la literatura de las propuestas por parte de algunos autores de pedagogías interaccionistas, plantear y discutir las similitudes encontradas en diferentes publicaciones. Se espera que el artículo contribuya a una mejor comprensión de este tipo de propuestas de los profesionales que se ocupan de la enseñanza de los deportes, lo que facilita la comprensión de sus características similares y que ejemplifica las posibilidades de intervención.

Palabras-Clave: Metodología; Pedagogía del deporte; Interaccionismo 


\section{O CENÁRIO da PEDAgogia do eSPORTE e AS PROPOSTAS INTERACIONISTAS}

A contemporaneidade é marcada pela velocidade e volume das mudanças nos mais variados setores que envolvem a existência humana. O mesmo podemos verificar no que se refere ao esporte, que vem apresentando evoluções e inovações em todos os seus setores. Como exemplo pode-se verificar os equipamentos esportivos como os calçados com alta tecnologia conferindo conforto e amortecimentos como jamais visto; as técnicas de treinamento físico que continuam levando o homem a superar seus recordes; a evolução nas tecnologias midiáticas levando aos espectadores imagens cada vez mais nítidas a cada vez mais pessoas; o mercado esportivo que se tornou uma das maiores indústrias econômicas do mundo.

Nesta mesma tendência, estudos que tratam do ensino dos esportes, denominada como pedagogia do esporte por diversos autores que serão discutidos neste artigo, também trazem inovações, procurando superar modelos tradicionais que apresentam características que não são mais admitidas em espaços educacionais que atuam com o esporte, embora não possam ser totalmente desconsiderados ou entendidos como propostas não produtivas, pois foi através delas que muitas pessoas aprenderam modalidades esportivas, aprenderam a gostar da prática e até se tornaram atletas de alto rendimento.

Segundo Scaglia e Reverdito, ${ }^{1}$ a pedagogia tradicional é aquela baseada na reprodução de modelos e padrões pré-determinados, exigindo muitas vezes pré-requisitos para a prática esportiva, podendo torná-la, em qualquer nível, excludente. Tais modelos e padrões determinados são impostos sem observação do contexto em que se ensina a modalidade, sem consideração com os anseios, necessidades e características dos educandos.

Situação colocada também como problemática diz respeito ao ensino do esporte pela mera repetição das experiências que o professor teve em sua trajetória como atleta, ou pior, o ensino de forma intuitiva, sem bases conceituais, nem mesmo oriundas de experiências passadas, sendo administradas por pessoas totalmente leigas, em geral, apenas com boa 
vontade. $^{1-2}$

Muitos autores também criticam as propostas que lidam com crianças e jovens de forma semelhante ao tratamento dado aos atletas de alto rendimento. A expressão "adultos em miniatura" já é bastante conhecida para identificar tal incoerência. Uma das causas prováveis deste fato é também outro problema encontrado tradicionalmente no ensino do esporte: ter por objetivo fundamental vencer, a qualquer custo, se necessário.

Infelizmente a valorização do mérito, do esforço e da superação costumam ficar sempre em segundo plano diante o valor do resultado, principalmente diante do Campeão!

As repercussões são variadas, como a exclusão dos menos aptos, os estímulos acima do suporte físico, psicológico e cognitivo de crianças e jovens, a especialização precoce, as aulas de EF com características de treinamento, ignorando conteúdos da cultura corporal em detrimento de poucas modalidades escolhidas, a valorização de professores vitoriosos (sem se considerar os meios para a vitória) em detrimento dos professores que se importam com a formação dos jovens, porém sem objetivar a busca pelos resultados esportivos como única meta a ser atingida.

Ainda com relação aos métodos tradicionais, a característica de ensino das técnicas de forma exaustivamente repetitiva e mecânica, para somente após seu perfeito domínio serem utilizadas em momentos de jogo, também é bastante criticada, alegando-se que, desta maneira, o praticante consegue executar um fundamento técnico com facilidade, mas ignora sua função, o momento e motivo adequados de utilização.

Com relação às táticas, estendendo-se também à execução das técnicas, também são criticadas as formas de ensinar ditando o que cada aluno deve realizar. Neste caso o professor/técnico é o mentor de todo o processo, é ele que determina e resolve os problemas cabendo aos alunos obedecer motoramente de forma eficiente.

Assim como Scaglia e Reverdito ${ }^{1}$ conceituam e caracterizam a pedagogia tradicional, eles também o fazem apresentando novas propostas, chamando-as de pedagogias interacionistas, Conexões: revista da Faculdade de Educação Física da UNICAMP, Campinas, v. 12, n. 4, p. 51-68, out./dez. 2014. 
tendo por característica o estímulo da criatividade e diversidade. Apesar de não serem propostas tão recentes, sendo discutidas, em sua maioria, a partir da década de 1990, se já não representam muita novidade no meio acadêmico, ainda são inovações em muitos espaços onde se ensina esporte pelo país.

As propostas em que se baseia este estudo são:

-Jogo possível de Roberto Paes ${ }^{3,13-14}$

-Esporte e inteligências múltiplas de Hermes Balbino; ${ }^{4}$

-Jogos Desportivos Coletivos de Júlio Garganta, ${ }^{5}$ Amandio Graça, ${ }^{6}$

-Teaching Games for Undertanding (Ensino de jogos pela compreensão), de Griffin e Oslin, ${ }^{7}$ Adriano Souza; ${ }^{8}$

-Pedagogia do jogo de João Batista Freire ${ }^{9}$ e Alcides Scaglia; ${ }^{10,23}$

-Escola da bola de Kroger e Roth; ${ }^{11}$

-Pedagogia do Esporte de Nista-Piccolo. ${ }^{12}$

As denominações acima atribuídas às propostas dos autores não foram necessariamente sugeridas pelos autores, mas acredita-se que identificam cada estudo.

O objetivo deste estudo foi identificar, descrever e discutir as aproximações encontradas nas diferentes propostas. Consideram-se como aproximações as orientações para o ensino de esportes que cada autor traz que tenham semelhança com as de outros estudiosos.

Para o levantamento de tais aproximações realizou-se revisão bibliográfica a partir das obras dos autores acima listados e de outras publicações relacionadas à pedagogia do esporte que pudessem contribuir para reforçar os temas elencados.

Como forma de melhor expor e discutir as características semelhantes propostas pelos diferentes autores para o ensino do esporte são apresentadas a seguir na forma de itens e com denominações que sintetizam seus propósitos, não assumindo necessariamente as denominações dos diferentes autores. São elas:

1- O aluno como foco central das ações; 
2- Ensinar mais que esporte;

3- Inclusão: jogo para todos;

4- Pilares norteadores para o ensino que se realizam diretamente no cotidiano das aulas:

- Orientação de ensino do jogo para suas partes;

- Adaptação de materiais, regras e espaços;

- Estímulos através de resolução de problemas e

- Valorização do conhecimento prévio do aluno.

Destacadas as aproximações seguem suas discussão e considerações:

\section{O ALUNO COMO FOCO CENTRAL DAS AÇÕES}

Como foi exposto anteriormente, em muitos espaços de formação esportiva e consequentemente, as atitudes de seus profissionais estão voltados principalmente para a busca por vitórias. Em tais exemplos, elevar a equipe ao status de campeã parece justificar quaisquer meios.

No sentido de se afastar desta realidade, as propostas pedagógicas interacionistas focam-se no aluno que aprende. Paes ${ }^{13,14}$ e Scaglia ${ }^{10,15}$ salientam, como aspecto importante quando se realiza uma proposta de ensino, entender quais são os personagens dessa prática, quais suas intenções, anseios, motivações.

Garcia $^{16: 326}$ reforça que "[...] mais importante que tentar definir desporto é tentar perceber o praticante, ou seja, o homem praticante do desporto".

Bianco $^{2: 25}$ também corrobora com o tema, afirmando que:

[...] no movimento da reforma atual do sistema educativo em geral e da educação física em particular, o aluno ocupa uma posição central ao ser considerado o construtor ativo das suas próprias atividades, em que são valorizados os processos cognitivos, a tomada de decisão e a compreensão das situações-problema.

Desta forma, o aprendiz se torna o centro das atenções e intenções da proposta de ensino do 
esporte. Como exemplo é possível prever que um grupo de jovens selecionados entre muitos por desempenho e porte físico adequado para a formação de equipes de base voltados para o esporte de alto rendimento não deva ter os mesmos estímulos que um grupo de mesma idade, participantes de um projeto social em comunidades periféricas, reunidos pelo desejo de praticar algum esporte.

É possível imaginar em ambos que o ensino deva conduzi-los à compreensão da modalidade, ao aprendizado contínuo, aos desafios por superarem suas dificuldades, enfim, a praticarem um bom jogo. No entanto, os objetivos devem ser diferentes. Ao primeiro, estímulos para forjar o futuro atleta e ao segundo, oportunizar o esporte como possibilidade de aprendizados diversos que contribuam para sua emancipação, mesmo considerando que nas duas situações os aprendizados preponderantes de um aconteçam também no outro e vice-versa.

\section{ENSINAR MAIS QUE ESPORTE}

É necessário ensinar esporte a todos, ensinar a gostar do esporte, ensinar bem esporte, ensinar mais que esporte a todos, afirmou Freire. ${ }^{17}$ Mais uma vez propõe-se o afastamento dos modelos que se baseiam unicamente no ensino das técnicas e táticas esportivas. Objetiva-se, nas propostas interacionistas, o ensino de conteúdos que extrapolam o fazer gestual próprio das modalidades, a exemplo de valores morais, a estimulação da criticidade, a mídia e o esporte como ferramenta política, social e econômica, entre muitos outros temas que perpassam este universo e que podem ter grande penetração nos jovens dado o significado que o esporte passa a ter em suas vidas.

Valorizar o esforço cotidiano e destacar os avanços combinados com discussões sobre a utilização de anabolizantes e suas consequências pode proporcionar a assimilação de atitudes saudáveis. A reflexão sobre os motivos de sua modalidade (à exceção do futebol) não ser televisionada com frequência em detrimento do futebol, pode formar um admirador das escassas oportunidades de assistir outras opções esportivas, caracterizando-se, ainda que de forma mínima, um contraponto ao que está posto atualmente, ou seja, em termos esportivos, um monopólio da "paixão nacional”. Estes são possíveis exemplos de temas que podem ser tratados no ambiente do ensino esportivo. 
Reverdito e Scaglia, ${ }^{1: 133}$ defendendo a contribuição da pedagogia do esporte na formação integral de seus educandos, apresenta a posição de outro autor:

Paes ${ }^{13-14}$

observa que na prática esportiva coabitam múltiplas possibilidades de expressões socioeducativas, nas quais estão para além do seu conteúdo e seus pressupostos metodológicos e procedimentais. No processo de ensino-aprendizagem, deverão ser considerados harmoniosamente os valores e os modos de comportamento. As observações feitas pelo autor atêm-se à formação do indivíduo por meio da prática esportiva, permitindo ao educando observar conscientemente sua prática e refletir criticamente seus significados e ressignificados.

Santana ${ }^{18: 19}$ colaborando com a proposição de que, ao se ensinar esporte, deve-se ensinar para além dele próprio, afirma que:

[...] os alunos nas aulas de esporte precisam rever, além das suas ações motoras, as suas atitudes morais. Estas tanto quanto aquelas são práticas (na verdade confundem-se). Logo, a pedagogia precisa dar conta disso. Compreender as próprias ações, motoras ou sociais, evitará, por um lado, que as crianças façam a prática pela prática, isto é, que não compreendam o que fizeram, que não tragam para o plano mental, para o centro, o que está apenas na periferia. De outro lado, poderá significar um aprendizado generalizável para a vida fora da quadra, ou seja, termina a aula de futsal, mas as coisas compreendidas na aula se estendem, pois pertencem à pessoa, e, portanto, se generalizam para situações cotidianas.

\section{INCLUSÃO: JOGO PARA TODOS}

Ainda parafraseando Freire, ${ }^{16}$ é necessário ensinar esporte a todos. Logicamente não significa que o esporte deve passar a ser uma obrigação, mas uma opção viável a todos os que se interessarem e, conforme o autor, ensinar aqueles que ainda não conhecem a querer aprender também.

A exclusão foi um dos motivos do esporte ter sido duramente criticado por tendências renovadoras na Educação Física principalmente a escolar, pois ela foi fruto da busca por atletas e vitórias no passado não tão distante e desta forma, interessava apenas os mais habilidosos ou os que apresentavam melhor potencial.

É fato que o esporte competitivo pode assumir características pouco democráticas onde nem toda pessoa se adequa, especialmente quando se objetiva o resultado como alvo principal. Conexões: revista da Faculdade de Educação Física da UNICAMP, Campinas, v. 12, n. 4, p. 51-68, out./dez. 2014. 
No entanto, a prática esportiva não se resume a ganhar ou perder e, portanto, uma proposta que se preocupa em ensinar esporte a todos deverá adequar as atividades competitivas aos seus alunos elencando objetivos claros e coerentes ao seu grupo, como ênfase no processo de aprendizado em detrimento da importância obsessiva pela vitória, adequação do nível de adversários a exemplo da formatação de festivais com categorias diferenciadas de forma que equipes de performance muito desiguais não se confrontem constantemente, ampliação do número de partidas vivenciadas evitando-se os sistemas de eliminação simples, conforme defendem Hirama e Montagner. ${ }^{19}$

Para além do âmbito competitivo, o esporte deve ser ensinado a todos como forma de apropriação desta cultura corporal, como forma saudável e prazerosa de prática de atividade física e também como conhecimento mais aprofundado e significativo. Santana ${ }^{18: 53}$ reforça a questão da inclusão de todos a partir do planejamento e atenção naquele que aprende:

Ora, se a motivação para aprender está na pessoa e ela aprende agindo sobre o que se pretende conhecer, aprenderá quem se mobilizar. Logo, a pedagogia precisa planejar isso. Como? Selecionando situações de aprendizado que despertem o interesse, que promovam um certo desequilíbrio em quem aprende, o que será possível se o nível de desenvolvimento e a história de vida de cada criança forem considerados. Garantindo-se o interesse, garante-se a conduta.

E ao se garantir o interesse por meio de proposta adequada, abre-se o espaço para a inclusão de todos os que se inclinarem a, como afirma o autor, se mobilizar. Mais adiante, daqueles que vivenciaram uma boa prática esportiva espera-se que estimulem o mesmo com seus próximos, construindo desta forma, uma rede de praticantes, admiradores e reivindicadores do bom esporte.

\section{PILARES NORTEADORES PARA O ENSINO DO ESPORTE}

Os pilares que serão descritos a seguir orientam a dinâmica da aula de esportes propriamente dita e são compostos por 4 temas:

\subsection{Orientação do jogo para as partes}

É possível admitir que esta orientação seja a base as das propostas interacionistas. Os demais pilares se apresentam no sentido de permitir que o jogo seja vivenciado da melhor maneira 
possível por aquele que aprende.

Orientar o aprendizado a partir do jogo significa que a modalidade será sempre apresentada aos alunos em sua forma mais complexa, ou seja, em sua dinâmica geral, observando-se, claro, o nível de entendimento dos aprendizes:

As crianças devem primeiramente aprender 'somente' a jogar com liberdade, reconhecer e perceber situações de forma correta e compreendêlas desde o ponto de vista tático [...] 'jogar se aprende jogando'. Kroger e Roth. ${ }^{11: 10}$

Souza $^{8}$ chega a afirmar que a resposta coerente do professor que atua com tais propostas, diante da pergunta tradicional das crianças: Professor, hoje vai ter jogo? Deva ser: Claro, todo dia tem jogo!

A justificativa para esta orientação é a de estimular no aprendiz o entendimento da dinâmica da modalidade como seus objetivos, espaços ocupados, regras básicas, possibilidades de execução. A partir deste entendimento, se estimula o aprendizado das partes do jogo, como seus fundamentos técnicos e táticos, mas agora, de forma consciente, oportunizando que o aluno compreenda a sua execução, onde e quando tal movimento acontecerá no jogo. Caso a estimulação seja realizada de forma contrária a esta lógica, alguns problemas podem surgir, como ressalta Greco: $:^{20: 38}$

Nos esportes coletivos, realizar um treinamento técnico de forma isolada, sem conexão com a situação de jogo é equivocado e conduz a automatismos rígidos, pouco flexíveis e invariáveis, o que leva à repetição inadequada na situação de competição.

Como exemplo é possível citar a dinâmica do jogo o voleibol que se fundamenta em defender um espaço, seu lado da quadra, não permitindo que a bola atinja o solo e buscando colocála no solo da quadra de seu adversário. Para tanto é necessário atuar apenas com rebatidas na bola e ocupar o espaço da melhor forma possível observando algumas mudanças de posição contidas na regra. Inicialmente é provável que a forma de se evitar que a bola caia seja pouco eficiente, o que levará os alunos a entenderem a importância de se aprender seus fundamentos, como manchete e toque, tornando a repetição dos gestos técnicos algo que possui significado, intenção.

No entanto, se não for oportunizada a vivência do jogo, o aprendizado de suas técnicas será Conexões: revista da Faculdade de Educação Física da UNICAMP, Campinas, v. 12, n. 4, p. 51-68, out./dez. 2014. 
descontextualizadas, sem relação com suas funções. Como consequência é possível se produzir exímios executores de técnicas, a exemplo das pessoas muito habilidosas em controlar uma bola com os pés fazendo "embaixadinha", mas que não garante que a mesma seja um bom jogador de futebol por não compreender a dinâmica da modalidade.

\subsection{Adaptação de materiais, regras e espaços}

Para ser possível a vivência do jogo para iniciantes e também para se adequar a dinâmica conforme os diferentes níveis de desempenho defende-se a adaptação das regras, materiais e/ou espaços com relação ao formato padrão da modalidade: "Alterar as regras para que os alunos possam competir sem grandes habilidades, e assim tentar motivar as crianças ou jovens." $8: 37$

Este pilar se concentra na necessidade de modificar o ritmo do jogo, de forma que ele seja possível acontecer, mas sem perder a essência de sua dinâmica, sem o

O ponto de partida desta abordagem assenta na formulação de uma forma modificada do jogo, necessariamente mais simples, adequada aos níveis actuais de interpretação dos alunos e ao mesmo tempo facilitadora da aquisição dos conceitos e competências associados à operacionalização da idéia de bom jogo para esse nível. ${ }^{6: 67}$

No entanto, não necessariamente a adaptação acontece sempre no sentido de tornar o jogo mais fácil, mas de procurar estimular determinada situação que possa ser necessária desenvolver no grupo ou equipe. Costa, ${ }^{21: 157}$ reforça a questão:

Mas para a aprendizagem e aprofundamento dos conhecimentos no jogo, tão importante quanto simplificar as regras, são as adaptações realizadas para dificultar o jogo, provocando um desequilíbrio no entendimento do aluno. Isso pode levá-lo a uma reflexão e, consequentemente, a uma nova forma de jogar, sendo que para isso é preciso desafiá-lo a ir além do que ele já sabe.

Como exemplo, uma equipe em que apenas um ou dois componentes finalizam as jogadas no handebol por motivo de maior habilidade. Este grupo é bastante vulnerável, pois basta a equipe adversária marcar tais jogadores para se anular o ataque. Para estimular uma maior variedade de situações nas quais os demais jogadores possam finalizar, uma adaptação de regra pode ser eficiente: o jogador que realizar o gol só poderá fazê-lo pela segunda vez após pelo menos outros 3 também realizarem os seus. 
Desta forma, é de se imaginar que os mais habilidosos façam seus gols primeiramente, no entanto, depois disto, serão "obrigados" a cooperarem com seus colegas de time para que estes também tenham sucesso para então poderem ter direito ao gol novamente, tornando o jogo da equipe mais coletiva, exigindo ações diferentes das anteriores, enfim, dificultando o jogo através da adaptação de regras para estímulos mais complexos.

\subsection{Estímulos através de resolução de problemas}

A função do professor nas propostas interacionistas é a de mediador e problematizador. No exemplo anterior o problema é posto à equipe: mais pessoas precisam ser acionadas para realizar os gols e não somente os mais habilidosos. Exige-se maior cooperação, em especial daquele que já realizou seu gol. No entanto, o professor deve se privar de ditar aos seus alunos o que fazer. É preciso que os próprios jogadores percebam a situação, reflitam individual e coletivamente sobre as estratégias a serem seguidas e colocá-las em prática.

Desta forma, o professor estará estimulando no grupo a resolução, a discussão sobre possibilidades, a criação de táticas e a autonomia coletiva. Assim o profissional se afasta da forma tradicional de lidar com seus alunos como o chefe que manda e os comandados que apenas executam, sem sequer entender o que fazem. O objetivo é o de desenvolver a inteligência para o jogo, a compreensão da modalidade, como também aspectos de relacionamento como liderança, autonomia, trabalho em grupo, propor ideias e defendê-las, ouvir as dos colegas e acatá-las ou não, agir conforme o acordado coletivo:

As estratégias utilizadas visavam à criticidade, possibilitando às crianças a troca de ideias entre si, sempre em busca de um outro jeito de fazer. As tarefas tinham como objetivo a estimulação do raciocínio, a solução de problemas cada vez mais complexos..$^{12: 98}$

Segundo Graça ${ }^{6}$ são duas ordens de problemas que os jogadores deverão se deparar: os problemas da seleção da resposta adequada (o quê, o quando e o porquê) e os problemas relativos à realização da resposta motora (o como) e devem ser oferecidos desde a iniciação esportiva.

Importante frisar a inter-relação entre os pilares aqui destacados: ora, se é indicado desde a iniciação que se ofereçam problemas para as crianças resolverem e que se estimule o aprendizado a partir do jogo, logicamente tal jogo deverá ter suas regras adaptadas para que, 
conforme Griffin e Oslin ${ }^{7}$ defendem, diminua-se a velocidade da dinâmica, dando maiores oportunidades para pensarem taticamente. Ainda, se o problema deve ser resolvido através da compreensão e raciocínio do próprio aluno, é necessário que o professor valorize o conhecimento que o aluno já traz, pois será a partir dele que irá buscar suas resoluções.

\subsection{Valorização do conhecimento do aluno}

Valorizar o conhecimento que cada aluno traz é considerar que ninguém vem vazio ou que se deva esvaziá-los para só então ensiná-los. Werner, Thorpe e Bunker ${ }^{22}$ defendem que mesmo que as habilidades apresentadas para se resolver um problema do jogo não forem conformadas à especificidade dos gestos técnicos da modalidade, tais ações devem ser valorizadas, mediando a partir deste repertório a construção das técnicas mais adequadas.

Reverdito e Scaglia1:62 afirmam que: “O início do ensino nos esportes deverá contemplar o que o aluno já sabe, ou seja, sua historicidade motora, social e cultural."

Desta forma, é a partir da maneira como o aluno irá resolver os problemas apresentados nas atividades propostas que construirá sua participação no jogo, mediado pelo professor. Caso não se atente em valorizar as respostas apresentadas, da forma que eles conseguiram realizar diante dos problemas propostos, é possível desmerecer totalmente seu conhecimento. Esta situação muitas vezes se dá através de expressões ainda comuns provenientes dos professores como: Não, assim está errado! Faça do jeito que te mostrei!

Percebe-se nas expressões anteriores a diretividade do profissional, o menosprezo pela forma do aluno tentar resolver a situação e ainda, a resposta dada pelo docente, que impõe uma forma que acha correta, não permitindo que haja liberdade de criação. A mensagem parece clara: Faça do jeito que eu te ensinei, pois a do seu jeito não é boa!

Um exemplo clássico que pode justificar o combate ao tratamento descrito é a de esportistas famosos que não seguiram os padrões motores consagrados por suas modalidades na execução de determinados fundamentos, mas mesmo assim foram atletas de destaque internacional, a exemplo de Magic Paula, jogadora de basquete que realizava o arremesso bastante diferente do padrão do jump, mas que foi considerada umas das melhores jogadoras e cestinhas de sua época.

Conexões: revista da Faculdade de Educação Física da UNICAMP, Campinas, v. 12, n. 4, p. 51-68, out./dez. 2014. 


\section{CONCLUSÃO}

A valorização do conhecimento do aluno também diz respeito aos anseios e desejos que cada aprendiz traz consigo. O que leva uma criança a ingressar numa escola de basquete, futebol ou vôlei? Será fazer cestas, gols ou cortadas? Provavelmente sim. Mas, caso não se permita que ela jogue ou se tal jogo não for adaptado ao seu atual nível de entendimento e desempenho, a possibilidade de fracasso é grande. Quantas crianças e jovens não iniciaram em escolas de esportes com desejos de serem Ronaldinhos, Michael Jordans, Magic Paulas, Gibas, mas após frequentarem poucos meses de aula e nunca conseguirem realizar um gol, uma cesta ou uma cortada, abandonam a prática e o que é pior, com o sentimento de que não são capazes, de que não nasceram para isto? Quando provavelmente, faltou ao professor a sensibilidade em valorizar seus desejos e oportunizar jogos adaptados em que cada um consiga resolver os desafios adequados aos seus níveis e por fim terem sucesso.

A superação, o enfrentamento das frustrações, o esforço devem fazer parte do esporte, mas tudo deve ser oferecido ao seu tempo e no nível adequado. Neste exemplo, é necessário primeiro que a criança entenda o jogo, aprenda a gostar dele, tenha sucesso, faça gols, cestas e cortadas para depois enfrentar desafios mais exigentes, pois então, ela sabe o quanto vale a pena.

Como alcançar este ambiente de aprendizagem? Este estudo procurou destacar algumas características que podem constituir um possível caminho. Não por acaso, considerar o aluno como centro de toda a ação pedagógica foi a primeira aproximação discutida. Nele está contida (ou deveria estar) toda a razão da existência de qualquer programa de ensino do esporte. Seus desejos, ambições, limites, fragilidades, necessidades devem nortear a proposta pedagógica esportiva.

E, mantendo-se o aluno no plano principal, as demais características levantadas se agregam. Ao se ensinar esporte deve se aprender mais do que esporte, pois aspectos como valores morais, relações sociais, políticas e econômicas, qualidade de vida, entre muitos outros, se tornam possibilidades significativas a serem abordadas, visto que várias situações aproximam o aprendiz do conceito aliado à experiência. 
Ainda considerando o aluno como o componente principal das ações, a preocupação em incluir todos os desejosos por aprender estará contemplada, estimulando o professor a planejar ações que garantam a participação para além de estarem presentes, de forma a manter o aprendizado desafiador, considerando as diferenças de cada jovem.

Ao leitor menos familiarizado com as propostas aqui discutidas, o ambiente defendido pode parecer bastante complexo e difícil de ser construído. No entanto acredita-se que os quatro pilares norteadores para o ensino do esporte apresentadas como último item das aproximações colaborem para a construção deste cenário pedagógico, atuando como facilitador de todas as características anteriores.

Alguns exemplos pontuais de intervenção e ambientes descritos foram oriundos das experiências dos autores com o ensino do esporte por meio das propostas aqui discutidas. Percebe-se que a investigação científica de tais intervenções e suas consequências representam um novo desafio para os estudiosos da pedagogia do esporte: o levantamento de indicativos científicos coerentes que reforcem as hipóteses expostas pelas propostas interacionistas e confirmem as impressões positivas de alguns professores que já vem aplicando tais proposições em diferentes espaços esportivos.

\section{REFERÊNCIAS}

${ }^{1}$ REVERDITO, R. S.; SCAGLIA, A. J. Pedagogia do esporte: jogos coletivos de invasão. São Paulo: Phorte, 2009.

${ }^{2}$ BIANCO, M. A. Capacidades cognitivas nas modalidades esportivas coletivas. In: DE ROSE JÚNIOR, D. (Org.). Modalidades esportivas coletivas. Rio de Janeiro, educação. Guanabara Koogan, 2006.

${ }^{3}$ PAES, Roberto R.; BALBINO, H. F. Pedagogia do esporte: contextos e perspectivas. Rio de Janeiro: Guanabara Koogan, 2005.

${ }^{3}$ BALBINO, H. F. Jogos desportivos coletivos e os estímulos das inteligências múltiplas:

Conexões: revista da Faculdade de Educação Física da UNICAMP, Campinas, v. 12, n. 4, p. 51-68, out./dez. 2014. 
bases para uma proposta em pedagogia do esporte. 2001. 142 f. Dissertação (Mestrado em Educação Física) - Faculdade de Educação Física, Universidade Estadual de Campinas, Campinas, Campinas, 2001.

${ }^{5}$ GARGANTA, J. Para uma teoria dos jogos desportivos colectivos. In: GRAÇA, A.; OLIVEIRA, J. (Org.). O ensino dos jogos desportivos. 2. ed. Porto: Universidade do Porto, 1995.

${ }^{6}$ GRAÇA, A.; OLIVEIRA, J. (Org.). O ensino dos jogos desportivos. 2. ed. Porto: Universidade do Porto, 1995.

${ }^{7}$ GRIFFIN, L. L.; MITCHELL, S. A.; OSLIN, J. L. Teaching sports concepts and skills: a tactical games approach. Champaign: Human Kinetics, 1997.

${ }^{8}$ SOUZA, A. J. É jogando que se aprende: o caso do voleibol. In: NISTA-PICOLLO, V. L. Pedagogia dos esportes. Campinas: Papirus, 1999.

${ }^{9}$ FREIRE, J. B. Pedagogia do futebol. Campinas: Autores Associados, 2003.

${ }^{10}$ SCAGLIA, A. J. Escola de futebol: uma prática pedagógica. In: NISTA-PICOLLO, V. L. Pedagogia dos esportes. Campinas: Papirus, 1999.

${ }^{11}$ KROGER, C.; ROTH, K. Escola da bola: um abc para iniciantes nos jogos esportivos. São Paulo: Phorte, 2002.

${ }^{12}$ NISTA-PICOLLO, V. L. Pedagogia dos esportes. Campinas: Papirus, 1999.

${ }^{13}$ PAES, R. R. Educação física escolar: o esporte como conteúdo pedagógico do ensino fundamental. Canoas: ULBRA, 2001.

${ }^{14}$ PAES, R. R. A pedagogia do esporte e os jogos coletivos. In: DE ROSE JR., D. Esporte e atividade física na infância e na adolescência: uma abordagem multidisciplinar. Porto Conexões: revista da Faculdade de Educação Física da UNICAMP, Campinas, v. 12, n. 4, p. 51-68, out./dez. 2014. ISSN: $1983-9030$ 
Alegre: Artmed, 2003.

${ }^{15}$ SCAGLIA, A. J. O futebol e o jogo/brincadeira de bola com os pés: todos semelhantes, todos diferentes. 2003. 164 f. Tese (Doutorado em Educação Física) - Faculdade de Educação Física, Universidade Estadual de Campinas, Campinas, 2003.

${ }^{16}$ GARCIA, R. P. Contributo para uma compreensão do desporto: uma perspectiva cultural. In: BARBANTI, V. J. et al. (Org.). Esporte e atividade física: interação entre o rendimento e a qualidade de vida. São Paulo: Manole, 2002.

${ }^{17}$ FREIRE, J. B. Pedagogia do Futebol. Londrina: Midiograf, 1998.

${ }^{18}$ SANTANA, W. C. A pedagogia do esporte e a moralidade infantil. 2003. Dissertação (Mestrado em Educação Física) - Faculdade de Educação Física, Universidade Estadual de Campinas, Campinas, 2003

${ }^{19}$ HIRAMA, L. K; MONTAGNER, P. C. Competição em esportes: "ingrediente" para uma proposta formativa. In: REVERDITO, R.; SCAGLIA, A. J.; MONTAGNER, P. C. Pedagogia do esporte: aspectos conceituais da competição e estudos aplicados. São Paulo: Phorte, 2013.

${ }^{20}$ GRECO. P. J. Iniciação esportiva II: metodologia da iniciação esportiva na escola e no clube. Belo Horizonte: Ed. da UFMG, 1998.

${ }^{21}$ COSTA, R. R. Aprender a jogar jogando: o modelo do teaching games for understanding. In: REIS, F. P. G.; ARRUDA, I. E. A. (Org.). Educação física escolar e pedagogia do esporte em perspectiva. Taubaté: Cabral, 2010.

${ }^{22}$ WERNER, P.; THORPE, R.; BUNKER, D. Teaching games for understanding: evolution of a model. Journal of Physical Education Recreation and Dance, Reston, v. 67, n. 1, 1996. 
${ }^{23}$ SCAGLIA, A. J. O futebol e as brincadeiras de bola: a família dos jogos de bola com os pés. São Paulo: Phorte, 2011. 208p.

Recebido em: 14 ago. 2014

Aceito em: 10 nov. 2014

Contato: leopoldohirama@yahoo.com.br 